\title{
The Lake Champlain Frontier as a Portal for Accidentally Introduced Asian Geckos
}

\author{
Aaron M. Bauer ${ }^{1}$ and Barry W. Baker ${ }^{2}$
}

\begin{abstract}
${ }^{1}$ Department of Biology, Villanova University, 800 Lancaster Avenue, Villanova, Pennsylvania 19085-1699, USA (aaron.bauer@villanova.edu) ${ }^{2}$ U.S. National Fish \& Wildlife Forensics Laboratory, Morphology Section, 1490 East Main Street, Ashland, Oregon 97520-1310, USA (barry_baker@fws.gov)
\end{abstract}

Althor lthough most gekkotan lizard species have very limited areas of endemism, a small number of species, including representatives of the gekkonid genera Hemidactylus, Lepidodactylus, Gekko, and Gehyra, have broad distributions that have been achieved, in part, through human agency. For the most part, such introduced geckos have become naturalized outside of their original ranges only in tropical or subtropical areas (Lever 2003, Kraus 2009). However, at least one species, the Mediterranean Gecko (Hemidactylus turcicus), has become established, albeit in very circumscribed pockets, in areas of the United States that experience more severe winters than any place in their native range (Norden and Norden [1989] 1991, Knight 1993, Bauer 2000).

Through the combination of increasingly rapid movement of goods internationally and increased border inspections, ever more geckos are both arriving alive and being discovered at temperate ports of entry around the world. In New Zealand, 189 records of exotic amphibian and reptile interceptions were generated during the period 1929-2000 (119 in the 1990s alone), of which geckos accounted for 101 (Gill et al. 2001). Many such stowaways travel trans-continentally by ship in massive containers and may easily escape

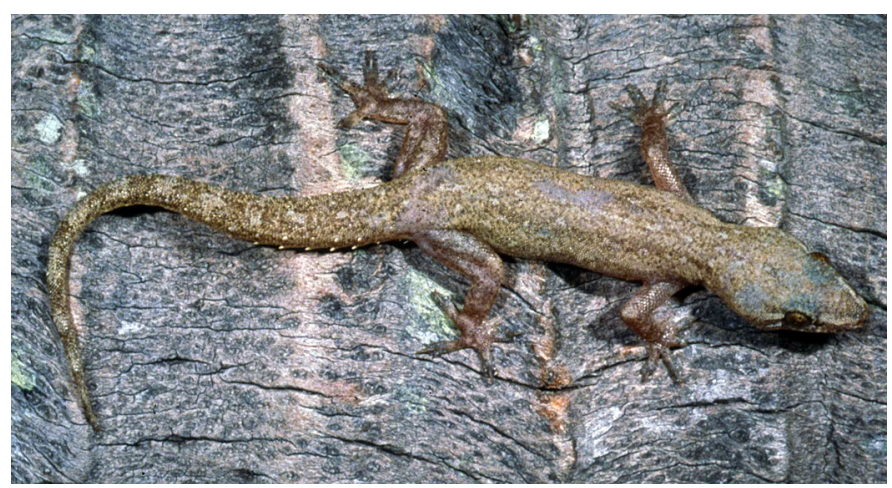

Fig. 1. Hemidactylus frenatus, one of the most widely introduced and established of all gecko species. Specimen from an introduced population in Nouméa, New Caledonia. Photograph by A.M. Bauer. detection. Most discoveries occur at or near their final destination, when shipments are being unpacked by buyers or inspected by customs, border control, or quarantine officials. For example, Gekko monarchus, a tropical Asian species, was found in a factory warehouse in Port Elizabeth, South Africa (Bauer and Branch 2004) and a specimen of G. hokouensis was intercepted by U.S. Customs and Border Protection personnel at the Port of Champlain, New York in a shipment of plastic liners that originated 35 days earlier in Qingdao, Shandong Province, People's Republic of China (Bauer and Baker 2008).

Judging by their establishment and naturalization around the world (Lever 2003, Kraus 2009), certain House Geckos of the genus Hemidactylus are among the most successful of all invasive gecko species. Their colonization of extralimital areas is assumed to have been primarily the result of accidental introductions through goods transport, although in some cases reptile importers or breeders have been implicated (Meshaka et al. 2004). In the United States, at least five species of Hemidactylus have become established, $H$. turcicus, $H$. mabouia, $H$. garnotii, $H$. frenatus, and $H$. (formerly Cosymbotus) platyurus. In southern Florida, all are present, and these geckos interact not only with the native fauna, but with one another, with the dynamics changing over time as newer arrivals become naturalized (Meshaka et al. 1994, 2004; Punzo 2005). While the southern states of the U.S. have long been the recipients of tropical colonizers and are at greatest risk for their establishment, global trade and transport have made it possible for exotic species to use virtually any entry point as a portal into the United States. We here report on two recent records of intercepted Hemidactylus spp. in the northeastern United States.

Specimen 1.-A juvenile Hemidactylus (CAS 250102, $40.48 \mathrm{~mm}$ SVL) was intercepted alive by an Agriculture Specialist (U.S. Customs and Border Protection) at Highgate Springs, Vermont on 18 August 2008. It had entered the U.S. via truck from the province of Québec, Canada in a 


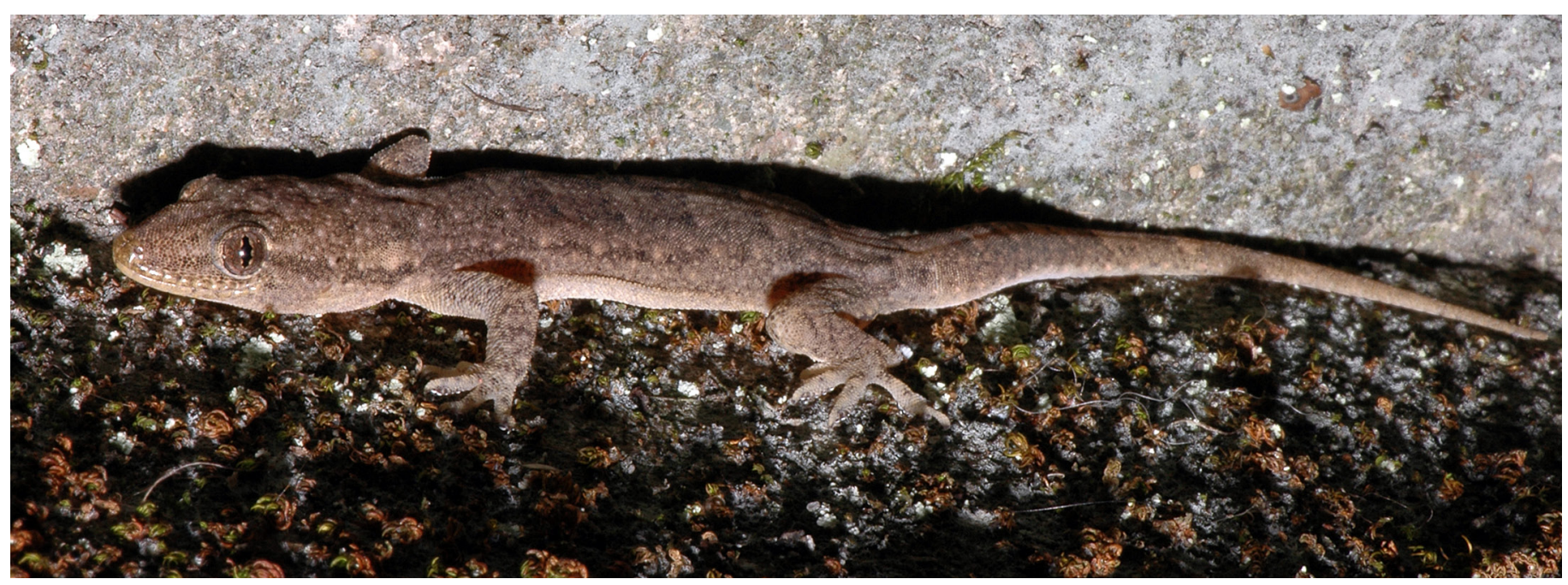

Fig. 2. Hemidactylus bowringii from WaWa Valley, New Taipei County, Taiwan. Although this species does not appear to be invasive, its occurrence on manmade structures makes it a likely candidate for accidental introductions in cargo shipments. Photograph courtesy of Ming-Chung Tu.

shipment of lawnmower parts. The shipment originated in Kaohsiung, Taiwan on 18 July 2008 and traveled by ship via Yantian, China (19 July), Hong Kong (20 July), Osaka, Japan (23 July), and Tokyo (24 July) and arrived in Tacoma, Washington on 1 August 2008. From Tacoma, the shipment traveled to Vancouver, crossing Canada by train to Montréal.

Only three species of Hemidactylus are recorded for Taiwan (Ota 1989, 1991; Lue et al. 1999; Shang and Lin 2008): $H$. bowringii, $H$. stejnegeri, and $H$. frenatus. Although similar in general appearance, only $H$. frenatus possesses dorsal tubercles (Fig. 1), which are clearly evident on the specimen.

Specimen 2.-A hatchling Hemidactylus (CAS 250103; $18.85 \mathrm{~mm} \mathrm{SVL}$ ) was found dead and partly dehydrated by an Agriculture Specialist (U.S. Customs and Border Protection) at the Port of Champlain, New York on 4 September 2008. It had entered the U.S. via truck from Canada in a shipment of toys from the Peoples Republic of China. Details of the shipment's port of origin and subsequent movements are unavailable, but like the first specimen, it is believed to have crossed Canada by train from Vancouver to Montréal before being trucked across the American border.

Mainland China supports five species of Hemidactylus: $H$. frenatus, $H$. bowringii, $H$. aquilonius, $H$. stejnegeri, and H. brookii (Zhao et al. 1999, Zug et al. 2007, McMahan and Zug 2007), the last of these probably introduced (Zhao and Adler 1993, Bauer et al. 2010). The intercepted specimen is atuberculate, a condition seen in $H$. bowringii (Figs. $2 \& 3$ ), $H$. aquilonius, and $H$. stejnegeri, but the configuration of the chin shields excludes the last of these species. The other two are extremely similar in morphology (McMahan and Zug 2007), and the desiccated state of preservation of animal precludes unambiguous species identification. However, $H$. bowringii is distributed from eastern Indochina through the industrialized regions of southeastern China and into Taiwan and the Ryukyus (McMahan and Zug 2007), whereas the recently described $H$. aquilonius occurs westward from Yunnan through Burma to Assam, in northeastern India (Purkayastha et al. 2010). Based on the circumstances of its translocation, we are confident that the specimen represents $H$. bowringii. Hatchlings of $H$. bowringii measure 18.5-19.8 mm SVL (Lazell 2002), thus given a transit time of approximately 30-35 days, the specimen probably hatched from an egg en route, possibly even an egg laid en route, given an incubation period of approximately one month (Karsen et al. 1998, Lazell 2002).

Although the severe winters of northern New York State or Vermont would prevent establishment of these tropical species, other American ports of entry, particularly along the Gulf Coast, could conceivably support the establishment of either of these gecko species. Hemidactylus frenatus has already been established in many areas of the word, including much of the tropical Pacific, parts of South America, and southern Florida, often arriving as a cargo stowaway (see Kraus 2009 and references therein). Climate-envelope modeling predicts that portions of the southeastern United States could provide suitable conditions for this species, particularly under predicted future climate-change scenarios (Rödder et al. 2008). Hemidactylus bowringii has not thus far been identified as an invasive species and has not become naturalized outside of its native range, but its ability to thrive in a diversity of habitats, from woodlands to urban settings (Lazell 2002), suggests a potential for establishment under the correct conditions. The nature of the interactions between these two Hemidactylus are unknown, but $H$. frenatus has been known to competitively exclude a variety of other gecko species, chiefly parthenogenetic forms, in areas where they have been introduced (Petren et al. 1993, Petren and Case 1996, Bauer and Sadlier 2000, Rivas et al. 2005), and thus might be detrimental under some 


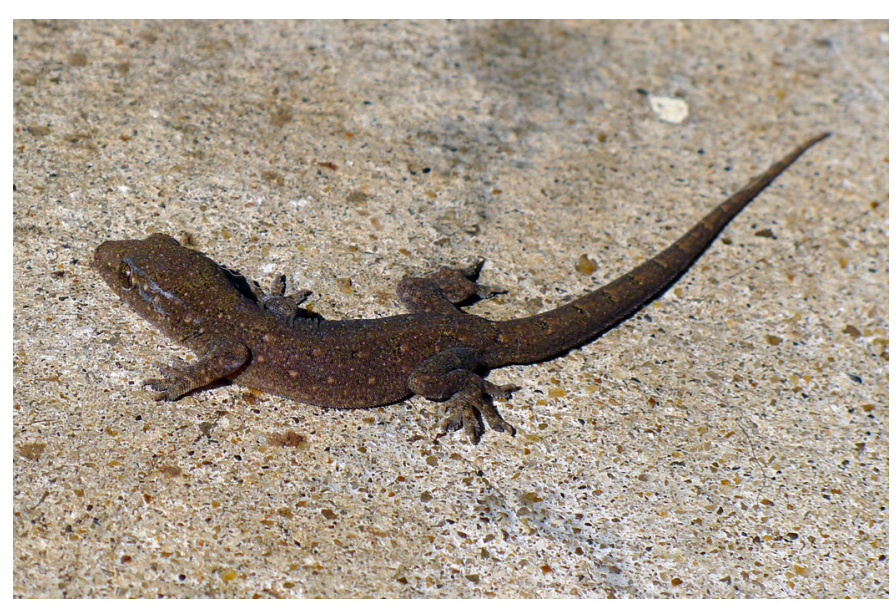

Fig. 3. Hemidactylus bowringii from Hong Kong, China. The subtle color patterning of the flanks, dorsum, and tail of this species as well as its smooth, atuberculate skin are clearly visible in this individual. Photograph courtesy of Michael Lau.

circumstances. Although neither of these Hemidactylus species is of current conservation concern, both are used as ingredients in traditional medicine (Jiang 1983, Nguyen 1993, Alves et al. 2008), and given the popularity of this practice (in both developed and developing nations) and the magnitude of international trade in other geckos so used (Bauer 2009), prospects exist for increased trans-border trafficking in both species.

The two specimens reported here, along with a third previously discussed by us (Bauer and Baker 2008) from the Lake Champlain region, indicate that this area serves as a potential portal for accidentally introduced geckos into the United States. Although certainly not as important a route of entry as much larger ports that receive direct imports from around the world, the region has recently become a concern for alien reptiles from the Asia-Pacific region due to faster and more efficient global transportation and transshipment. Continued monitoring of this and other potential invasion pathways is needed not only to prevent the establishment of new colonies of invasive species, like $H$. frenatus, but also to identify the arrival of species, such as $H$. bowringii, which, although not now established in the United States, have the potential to become invasive.

\section{Acknowledgments}

We thank the U.S. Customs and Border Protection (CBP) Agriculture Specialists who collected the specimens and Wildlife Inspector Robert Mulkeen (U.S. Fish \& Wildlife Service) for bringing them to our attention and providing details of shipping records. The opinions, findings, and conclusions presented here are those of the authors and do not necessarily represent the views of the U.S. Fish \& Wildlife Service. AMB was supported by National Science Foundation grant DEB 0844523.

\section{Literature Cited}

Alves, R.R.N., W.L.S., and G.G. Santana. 2008. Reptiles used in traditional folk medicine: conservation implications. Biodiversity and Conservation 17:20372049.

Bauer, A.M. 2000. How far north would the gecko move if the gecko could move north? Herpetological Review 31:72-73.

Bauer, A.M. 2009. Geckos in traditional medicine - forensic implications. Applied Herpetology 6:81-96.

Bauer, A.M. and B.W. Baker. 2008. An East Asian gecko (Gekko hokouensis, Gekkonidae) intercepted in Champlain, New York, USA. Applied Herpetology 5:197-198.

Bauer, A.M. and W.R. Branch. 2004. An accidental importation of Gekko monarchus into Africa. Hamadryad 28:125-126.

Bauer, A.M. and R.A. Sadlier. The Herpetofauna of New Caledonia. Society for the Study of Amphibians and Reptiles, Ithaca, New York.

Bauer, A.M., T.R. Jackman, E. Greenbaum, A. de Silva, V.B. Giri, and I. Das. 2010. Molecular evidence for the taxonomic status of Hemidactylus brookii group taxa (Squamata: Gekkonidae). The Herpetological Journal 20:129-138.

Gill, B.J., D. Bejakovich, and A.H. Whitaker. 2001. Records of foreign reptiles and amphibians accidentally imported to New Zealand. New Zealand Journal of Zoology 28:351-359.

Jiang, D.Q. 1983. Preliminary report on chemical analysis of Hemidactylus bowringii [in Chinese]. Zhong Yao Tong Bao 8(1):30-31.

Karsen, S.J., M.W. Lau, and A. Bogadek. 1998. Hong Kong Amphibians and Reptiles, Second Edition. Provisional Urban Council, Hong Kong.

Knight, C.M. 1993. A northern range extension of Hemidactylus turcicus in the United States. Dactylus 2(2):49-50.

Kraus, F. 2009. Alien Reptiles and Amphibians, a Scientific Compendium, and Analysis. Springer Verlag, Dordrecht, The Netherlands.

Lazell, J. 2002. The herpetofauna of Shek Kwu Chau, South China Sea, with descriptions of two new colubrid snakes. Memoires of the Hong Kong Natural History Society 25:1-82.

Lever, C. 2003. Naturalized Reptiles and Amphibians of the World. Oxford University Press, Oxford.

Lue, K.Y., M.C. Tu, and G.S. Shang. 1999. A Field Guide to Amphibians and Reptiles in Taiwan. Society for Wildlife and Nature, Taipei, Taiwan.

McMahan, D.C. and G.R. Zug. 2007. Burmese Hemidactylus (Reptilia, Squamata, Gekkonidae): Geographic variation in the morphology of Hemidactylus bowringii in Myanmar and Yunnan, China. Proceedings of the California Academy of Sciences $4^{\text {th }}$ Series 58:485-509.

Meshaka, W.E., Jr., B.P. Butterfield, and J.B. Hauge. 1994. Hemidactylus frenatus established in Florida. Herpetological Review 25:127-128.

Meshaka, W.E., Jr., B.P. Butterfield, and J.B. Hauge. 2004. The Exotic Amphibians and Reptiles of Florida. Krieger Publishing Co., Malabar, Florida.

Nguyen, X.T. 1993. A glimpse of the traditional medicines of animal origin, pp. 144-156. In: B.C. Hoang (ed.), Vietnamese Traditional Medicine. The Gioi, Hanoi, Vietnam.

Norden, A.W. and Norden, B.B. [1989] 1991. The Mediterranean gecko (Hemidactylus turcicus) in Baltimore, Maryland. The Maryland Naturalist 33:57-58.

Ota, H. 1989. A review of the geckos (Lacertilia: Reptilia) of the Ryukyu Archipelago and Taiwan, pp. 222-261. In: M. Matsui, T. Hikida, and R.C. Goris (eds.), Current Herpetology in East Asia. Herpetological Society of Japan, Kyoto.

Ota, H. 1991. Systematics and biogeography of terrestrial reptiles of Taiwan, pp. 47-112. In: Y.-S. Lin, and K.-H. Chang (eds.), Proceedings of the First International Symposium on Wildlife Conservation, ROC. Council of Agriculture, Taipei, Taiwan.

Petren, K. and T.J. Case. 1996. An experimental demonstration of exploitation competition in an ongoing invasion. Ecology 77:118-132.

Petren, K., D.T. Bolger, and T.J. Case. 1993. Mechanisms in the competitive success of an invading sexual gecko over an asexual native. Science 259:354-358.

Punzo, F. 2005. The introduction of hemidactyline geckos in Florida: Colonization and impact on native fauna, pp. 231-237. In: W.E. Meshaka, Jr., and K.J. Babbitt (eds.), Amphibians and Reptiles, Status and Conservation in Florida. Krieger Publishing Co., Malabar, Florida.

Purkayastha, P., M. Das, A.M. Bauer, S. Sengupta, and S.K. Dutta. 2010. Notes on the Hemidactylus bowringii complex (Reptilia: Gekkonidae) in India and a change to the national herpetofaunal list. Hamadryad 35:20-27. 
Rivas Fuenmayor, G., T. Barros, G.N. Ugueto, and A.M. Bauer. 2005. Expansion and natural habits of a successful colonizing gecko in Venezuela (Reptilia: Gekkonidae: Hemidactylus mabouia) and the discovery of $H$. frenatus in Venezuela. Herpetological Review 36:121-125.

Rödder, D., M. Solé, and W. Böhme. 2008. Predicting the potential distributions of two alien invasive housegeckos (Gekkonidae: Hemidactylus frenatus, Hemidactylus mabouia). North-Western Journal of Zoology 4:236-246.

Shang, G. and S. Lin. 2008. A Field Guide to Lizards in Taiwan [in Chinese].
Bigtrees Press, Taipei, Taiwan.

Zhao, E.M. and K.K. Adler. 1993. Herpetology of China. Society for the Study of Amphibians and Reptiles, Oxford, Ohio.

Zhao, E., K. Zhao, and K. Zhou. 1999. Fauna Sinica. Reptilia Vol. 2. Squamata. Lacertilia [in Chinese]. Science Press, Beijing, China.

Zug, G.R., J.V. Vindum, and M.S. Koo. 2007. Burmese Hemidactylus (Reptilia, Squamata, Gekkonidae): taxonomic notes on tropical Asian Hemidactylus. Proceedings of the California Academy of Sciences, 4th Series 58:387-405. 